AperTO - Archivio Istituzionale Open Access dell'Università di Torino

\title{
Genotyping of Polyomavirus BK by Real Time PCR for VP1 gene
}

\section{This is a pre print version of the following article:}

Original Citation:

Availability:

This version is available http://hdl.handle.net/2318/95277

since

Published version:

DOI:10.1007/s12033-011-9386-6

Terms of use:

Open Access

Anyone can freely access the full text of works made available as "Open Access". Works made available under a Creative Commons license can be used according to the terms and conditions of said license. Use of all other works requires consent of the right holder (author or publisher) if not exempted from copyright protection by the applicable law. 


\section{(3) \\ UNIVERSITÀ DEGLI STUDI DI TORINO}

The final publication is available at Springer via

http://link.springer.com/article/10.1007\%2Fs12033-011-9386-6 


\title{
2 Genotyping of Polyomavirus BK by Real Time PCR for VP1 Gene
}

\author{
3 Stefano Gambarino - Cristina Costa - Sara Astegiano • \\ 4 Elsa Alessio Piasentin - Giuseppe P. Segoloni · \\ 5 Rossana Cavallo $\cdot$ Massimiliano Bergallo
}

(C) Springer Science+Business Media, LLC 2011

Stefano Gambarino and Cristina Costa contributed equally to this work and share first authorship.

S. Gambarino - C. Costa $(\bowtie) \cdot$ S. Astegiano

E. A. Piasentin - R. Cavallo $\cdot$ M. Bergallo

Virology Unit, University Hospital San Giovanni Battista di

Torino, Via Santena 9, 10126 Turin, Italy

e-mail: cristina.costa@unito.it

S. Gambarino

e-mail: stefano.gambarino@unito.it

\section{S. Astegiano}

e-mail: sara.astegiano@unito.it

E. A. Piasentin

e-mail: epiasentin@molinette.piemonte.it

R. Cavallo

e-mail: rossana.cavallo@unito.it

M. Bergallo

e-mail: massimiliano.bergallo@unito.it

\section{G. P. Segoloni}

Renal Transplant Unit, University Hospital San Giovanni

Battista di Torino, Turin, Italy

e-mail: giuseppe.segoloni@unito.it strains or isolates were identified. Specific primers and probes for the detection and discrimination of each genotype by four Real-Time PCR assays were designed and technically validated. Subsequently, the four Real-Time PCR assays were used to test $20 \mathrm{BK}$-positive urine specimens from renal transplant patients, and evidenced a prevalence of BK genotype I, as previously reported in Europe. Results were confirmed by sequencing. The availability of a rapid and simple genotyping method could be useful for the evaluation of BK genotypes prevalence and studies on the impact of the infecting genotype on viral biological behavior, pathogenic role, and immune evasion strategies.

Keywords Polyomavirus BK · Genotyping - Real-time PCR $\cdot$ Sequencing $\cdot$ Prevalence

\section{Introduction}

BK virus (BKV) belongs to the Polyomaviridae family and has a circular double-stranded DNA genome of about $5100 \mathrm{bp}$ [1]. After primary infection that usually occurs in the childhood and, which is mainly asymptomatic, BKV remains latent at different sites, including the renourinary tract, B-cells, and brain [2]. Reactivation with viruria may occur, mainly in the context of immunosuppression, and potentially lead to nephropathy (BKV-associated nephropathy-BKVAN) in renal transplant recipients [3] or hemorrhagic cystitis in bone marrow transplant patients [4].

$\mathrm{BKV}$ is the only primate polyomavirus with serologically differentiated subtypes (I-IV) [5]. Jin and colleagues developed a genotyping method based on the amplification of the epitope region of the VP1 gene by polymerase chain reaction (PCR) and classified viral isolates in four different

\begin{tabular}{|l|lll|}
\hline Journal : Large 12033 & Dispatch : $\mathbf{1 6 - 2 - 2 0 1 1}$ & Pages : $\mathbf{8}$ \\
Article No. : $\mathbf{9 3 8 6}$ & $\square$ LE & $\square$ TYPESET \\
MS Code : MOBI-D-11-00032 & $\sim_{\mathrm{CP}}$ & $\checkmark$ DISK \\
\hline
\end{tabular}


genotypes (BKV I-IV) corresponding to the serological ones [6].

The geographical distribution of BKV subtypes has been investigated in different studies [7-10], evidencing a higher prevalence for BKV I worldwide and a minor but consistent occurrence of BKV IV, in particular in South-East Asia. On the other hand, the prevalence of BKV II and BKV III is very low with a higher presence of BKV III in the African continent. This genotyping method is based on the presence of single nucleotide polymorphisms (SNPs) conserved between the various isolates belonging to each of the four genotypes. Many different biomolecular procedures have been developed to detect and discriminate SNPs [11-14]; among these, the ARMS PCR [15] uses the discriminatory power of the terminal $3^{\prime}$ nucleotide to obtain a successful amplification only for the DNA strand with a correct complementariness.

In this article, we describe the design of four different Real-Time PCR assays which can detect and discriminate among the four main BKV genotypes (I-IV) as a valid substitute of DNA sequencing.

\section{Materials and Methods}

\section{BKV Sequences and Phylogenetic Analyses}

379 BKV VP1 sequences, belonging to the main four genotypes (I-IV), were obtained from three different articles [8-10] by extrapolation from the server Nucleotide (www.ncbi.nlm.nih.gov/nucleotide/). Nucleotide positions from 1663 to 1912 (Dunlop strain complete genome, GeneBank Access no. V01108) were considered to obtain 250-bp length DNA sequences. Subsequently, the VP1 DNA sequences were aligned using the software Clustal X (i.e., the graphical version, with windows interface, of the bioinformatic software Clustal W). This software, that incorporates a novel position-specific scoring scheme and a weighting scheme for down weighting over-represented sequence groups, is used for multiple sequence alignment and phylogenetic analysis, with the possibility to draw phylogenetic trees. The software BioEdit was used to manipulate the alignment for a clearer sight of differences between the aligned sequences. BioEdit software is a userfriendly tool for post-alignment modifications, with the possibility to emphasize few sequences, cut and paste them, and make other evaluations, such as restriction mapping. The BKV VP1 sequences were then used for Phylogenetic analyses. Clustal X, that was utilized to make a neighbor-joining phylogenetic tree, and the free software NJplot were employed to display the resulting tree. The confidence of branching patterns of the neighbor-joining tree was determined by bootstrap analysis, using a set of 1,000 replicates.

\section{Primers and Probes Design}

The alignment was screened to find "hot spots" of mutation specific for all the strains or isolates belonging to each genotype (Fig. 1). In the absence of a specific single nucleotide mutation, the occurrence of a different nucleotide combination between the genotypes was considered. Every mutation was evaluated as a possible target for designing of a set of primers able to recognize all the BKV strains belonging to a specific genotype and to discriminate between the others by a mismatch at the $3^{\prime}$ primer ending. The parameters that were taken into consideration for selecting the "hot spots" and discriminating the primers design were the presence of a unique sequence shared between the strains belonging to one genotype but not to the others, the $60^{\circ} \mathrm{C}$ melting temperature, and the possibility to design a Real-Time PCR probe in the most conserved nucleotide region inside the hypothetic amplicon.

Primers and probes were designed with the help of the software Primer Express $^{\circledR}$ v3.0 (Applied Biosystem, Cheshire, UK). The primers obtained were then analyzed with the Autodimer Software, an open-source tool that evaluates the hairpin and primer-dimer formation, with the aim of excluding the presence of factors that could alter the amplification efficiency. In order to include all the strains

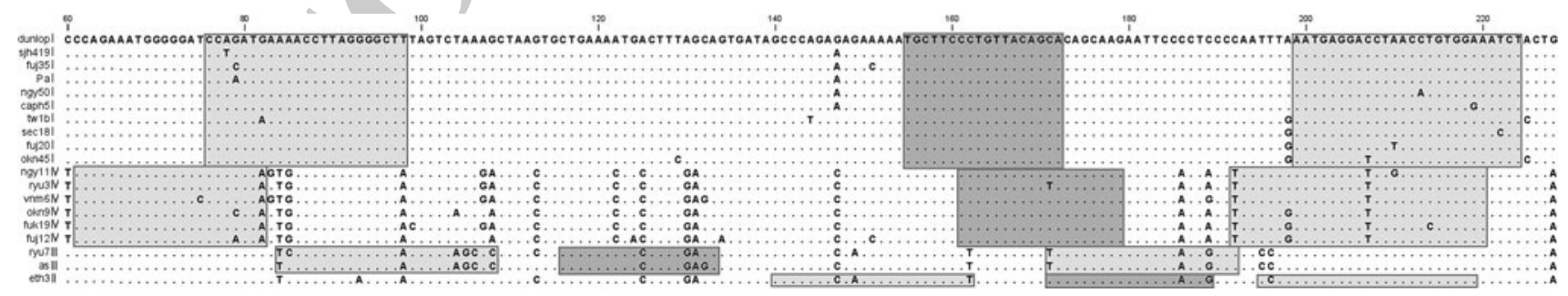

Fig. 1 Regions considered for the primer and probe design. Identical residues are represented as dots. Light squares indicate the primer regions. Dark squares represent the probe regions

\begin{tabular}{|l|lll|}
\hline Journal : Large 12033 & Dispatch : 16-2-2011 & Pages : 8 \\
Article No. : 9386 & $\square$ LE & $\square$ TYPESET \\
MS Code : MOBI-D-11-00032 & $\sim_{\text {CP }}$ & $\checkmark$ DISK \\
\hline
\end{tabular}




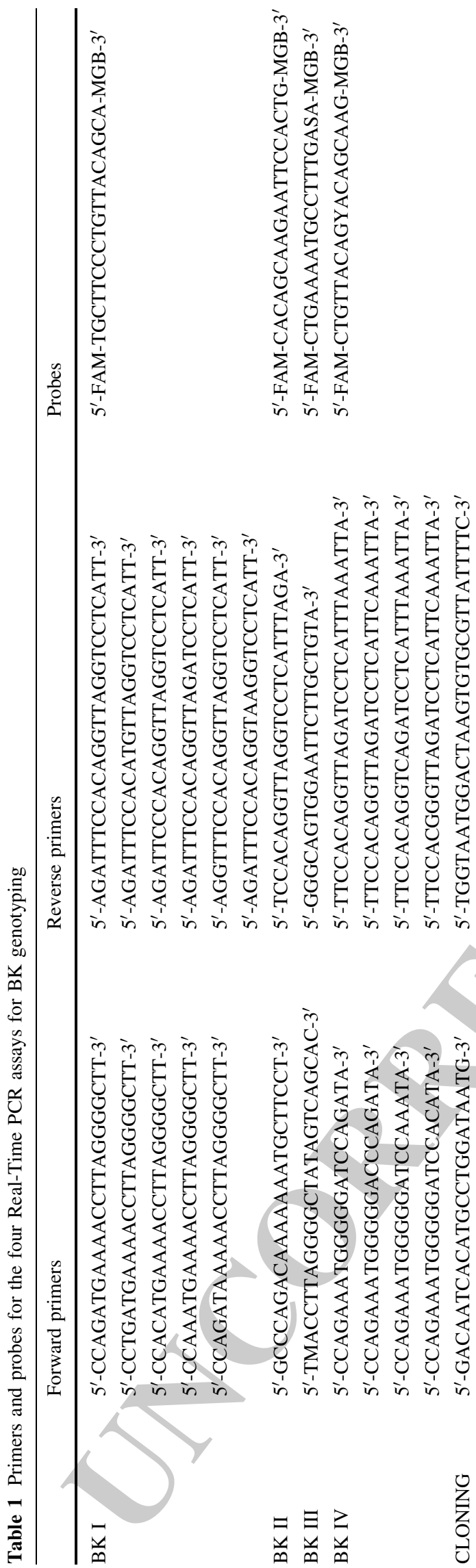

belonging to one genotype, many pairs of primers were designed and produced. Four Taqman ${ }^{\circledR}$ probes MGB (minor groove binding) labeled at the $5^{\prime}$ end with FAM (6-carboxyfluorescein), each being able to recognize one of the four target regions amplified by the different pairs of primers, were also designed. The list and sequences of primers and probes are reported in Table 1.

\section{Real-Time PCR Optimization}

Four different mixes for the amplification of each genotype were prepared. Different concentrations of primers and probe were evaluated: in particular, 200/200, 200/100, $100 / 200$, 200/50, and $50 / 200 \mathrm{nM}$ for primer forward/ reverse, and 250 or $100 \mathrm{nM}$ for probe. The reaction mixture contained $1 \times$ Master Mix (Platinum qPCR supermix-UDG with ROX [Invitrogen, Carlsbad, CA]). For this evaluation, isolates from BKV I (Dunlop strain) and BKV IV (kindly provided by Dr. Andi Krumbholz and Dr. Ellen Krautkramer), and ultramers that simulated BKV II and III sequences (comprehending a portion of isolates ETH3 and NEA27, respectively [Tema Ricerca, Bologna, Italy]), were used. Fifteen microliters of amplification mix were added to $5 \mu \mathrm{l}$ of BKV DNA, obtaining a final volume of $20 \mu \mathrm{l}$. The procedure was performed and optimized on the 7300 Real-Time PCR System (Applied Biosystems). The following thermal profile was used: one cycle of decontamination at $50^{\circ} \mathrm{C}$ for $2 \mathrm{~min}$, one cycle of denaturation at $95^{\circ} \mathrm{C}$ for $10 \mathrm{~min}$, and followed by 45 cycles of amplification at: $95^{\circ} \mathrm{C}$ for $15 \mathrm{~s}$, and $60^{\circ} \mathrm{C}$ for $60 \mathrm{~s}$. The following parameters were considered for the evaluation: quick observation of the amplification, and good discrimination between the specific and aspecific amplification.

The BKV I Dunlop standard plasmid was kindly provided by Prof. Tiziana Musso. The BKV II and BKV III standard plasmids were produced starting from the ultramers (Tema Ricerca), then amplified with cloning primers (Table 1). The BKV IV standard plasmid was prepared starting from the BKV IV isolate J/2296/04 (kindly provided by Dr. Andi Krumbholz). The primers were used for producing a PCR product, then cloned using the pTOPO-TA cloning system (Invitrogen) and propagated in competent Escherichia coli TOP10 cells. After overnight culture, selected transformed clones were amplified by culture in liquid LB medium $(10 \mathrm{~g}$ BACTOTRYPTONE, $5 \mathrm{~g}$ yeast extract, $171 \mathrm{mM}$ $\mathrm{NaCl}$, and $15 \mathrm{~g} / \mathrm{l}$ agar, $\mathrm{pH} 7.5$ ) containing $50 \mu \mathrm{g} / \mathrm{ml}$ of ampicillin. Plasmid DNA was extracted and purified using the Wizard Plus SV Miniprep DNA Purification System (Promega, Madison, WI). The plasmid concentration was estimated on spectrophotometric reading at OD260.

\begin{tabular}{|l|lll|}
\hline Journal : Large 12033 & Dispatch : 16-2-2011 & Pages : 8 \\
Article No. : $\mathbf{9 3 8 6}$ & $\square$ LE & $\square$ TYPESET \\
MS Code : MOBI-D-11-00032 & $\sim_{\mathrm{CP}}$ & $\checkmark$ DISK \\
\hline
\end{tabular}


Real-Time PCR Evaluation (Linearity, Efficiency, Interference Limit, Limit of Detection, Precision)

The four genotyping assays were evaluated using serial 10-fold dilutions of the target plasmid (ranging from $10^{7}$ to 10 copies per reaction). The linearity was assessed by the correlation coefficient $\left(R^{2}\right)$ of the standard curve obtained by plotting $10^{7}-10$ standard copies per reaction with the four different tests. The efficiency was evaluated by the slope of the standard curve, using the formula $E=10^{(-1 / \text { slope })}-1$.

In order to discriminate between specific and aspecific amplifications, three repetitions of $10^{7}, 10^{5}$, and $10^{3}$, and 10 copies per reaction of the four standards were amplified with the four different genotyping mixes. The average threshold cycle $(C \mathrm{t})$ values of specific and aspecific amplifications were obtained. The background $C \mathrm{t}$ was evaluated by the formula $C \mathrm{t}_{\text {lim }}=C \mathrm{t}_{\mathrm{a}}-\mathrm{t}_{0.01} \bullet \sigma_{\mathrm{a}} / N$, where $N$ is the number of observations, and $t_{0.01}$ is the tabulated value of Student's $t$ for the $1 \%$ probability level and $N-1$ degree of freedom [16]. For the evaluation of the lowest genotype concentration that could be distinguished from the aspecific amplification of the other three genotypes, the formula $I L=100 /\left(2^{\left({C \mathrm{t}_{\mathrm{s}}}-C \mathrm{t}_{\text {lim }}\right)}+\right.$ 1 was used, where $C \mathrm{t}_{\mathrm{s}}$ represents the specific $C \mathrm{t}$ [17].

The limit of detection, defined as the lowest target quantity detectable, was also estimated by serial 10 -fold standard dilutions. The precision of each test was calculated by the intra- and inter-test coefficients of variation, according to the formula $C V=100 \bullet(\sigma / M C)$, where $\mathrm{MC}$ is the average measured concentration, and $\sigma$ the correspondent standard deviation. Three repetitions for each standard dilution were considered in the same run or in different experiments, for the intra- and the inter-assay coefficients of variation, respectively.

\section{Clinical Specimens}

Twenty urine specimens resulting positive to a reference amplification assay (BKV Q-PCR Alert Kit [Nanogen, Buttigliera Alta, Turin, Italy]) were tested with the four amplification assays to assess the genotyping procedure. Automated DNA extraction was performed with the NucliSens EasyMAG platform (bioMeriéux, Marcy l'Etoile, France) from $1 \mathrm{ml}$ of urine, according to the manufacturer's instructions, and eluted to a final volume of $50 \mu \mathrm{l}$. Five microliters of extracted specimen were then added to $15 \mu \mathrm{l}$ of each genotyping mix. The results were analyzed using the System SDS software.

\section{Sequencing Procedure}

To confirm the results obtained by the Real-Time amplification, sequencing procedure was performed. The 20 specimens were amplified with primers BKV-1 (5'-GAA GTT CTA GAA GTT AAA ACT GGG-3') and BKV-2 (5'-GTG GAA ATT ACT GCC TTG AAT AGG-3') [9], obtaining an amplicon of 354 nucleotides within the VP1 gene (from 1663 to 2016, Dunlop reference numbering). The amplification mix contained $6 \mu \mathrm{l}$ of $\mathrm{GoTaq}^{\circledR}$ HotStart Polymerase buffer $5 \times$ (Promega), $200 \mu \mathrm{M}$ of each dNTP, $6 \mathrm{mM}$ of $\mathrm{MgCl} 2,1$ unit of $\mathrm{GoTaq}^{\circledR}$ HotStart Polymerase (Promega), and 20 pmol of BKV-1 and BKV-2 primers, respectively. The resulting amplicons were run on agarose gel $(2 \% \mathrm{w} / \mathrm{v})$ by electrophoresis, the gel was observed on an UV transilluminator UV and the bands cut. Subsequently, the bands were purified using the Nucleospin ${ }^{\circledR}$ Extract II (Macherey-Nagel, Düren, Germany). The purified PCR products were sequenced using the BigDye ${ }^{\circledR}$ Terminator v1.1 Cycle Sequencing Kit (Applied Biosystem). In brief, a mix containing $8 \mu \mathrm{l}$ of Terminator Ready reaction mix, $2 \mu \mathrm{l}$ of PCR product, 3.2 pmol of inner primer (BKV-1 or BKV-2), and deionized water to obtain $20 \mu \mathrm{l}$ final volume was prepared. Then, the Cycle sequencing was carried out on 9800 Fast Thermal Cycler (Applied Biosystem) with an initial denaturation step at $96^{\circ} \mathrm{C}$ for $1 \mathrm{~min}$, followed by 25 cycles of $96^{\circ} \mathrm{C}$ for $10 \mathrm{~s}$, $50^{\circ} \mathrm{C}$ for $5 \mathrm{~s}$, and $60^{\circ} \mathrm{C}$ for $4 \mathrm{~min}$.

The Cycle sequencing product was then purified by Ethanol/EDTA/Sodium Acetate precipitation and loaded onto the ABI PRISM 31 Genetic Analyzer (Applied Biosystem). Forward and reverse sequences were aligned with the ClustalX sotware and then compared to BKV sequences.

\section{Results}

The best amplification was obtained with the following concentrations of primers forward/reverse: 100/200, 200/200, 200/200 and 200/100 nM for genotypes I, II, III, and IV, respectively, and with a probe concentration of $250 \mathrm{nM}$; however, the amplification efficiencies were 104, 104,97 , and $88 \%$, respectively. The $R^{2}$ coefficient was $0.996,0.999,0.995$, and 0.999 for BK I, II, III, and IV genotype amplifications, respectively.

Subsequently, the Real-Time PCRs were tested for the discrimination of the four genotypes. Three repetitions of $10^{7}, 10^{5}$, and $10^{3}$, and 10 copies/reaction of the target sequence of the main four BKV genotypes were employed to compare the amplification and distinguish between specific and aspecific amplifications using the four mixes (Table 2). As regards the BKV I genotype mix, this resulting product was able to amplify the genotype I-specific target, and only BKV II and IV genotype mixes cross-recognize the specific genotype I target at $10^{7}$ copies/reaction (both), and at $10^{5}$ copies/reaction (only the BKV II genotype mix). However, a

$\begin{array}{lll}\text { Journal : Large 12033 } & \text { Dispatch : } \mathbf{1 6 - 2 - 2 0 1 1} & \text { Pages : } 8 \\ \text { Article No. : } \mathbf{9 3 8 6} & \square \text { LE } & \square \text { TYPESET } \\ \text { MS Code : MOBI-D-11-00032 } & \sim_{\text {CP }} & \checkmark \text { DISK }\end{array}$


Table 2 Aspecific and specific means $C t$ for each genotyping mix

\begin{tabular}{|c|c|c|c|c|c|}
\hline & \multirow{2}{*}{$\begin{array}{l}\text { Specific mean } C \mathrm{t} \\
\text { BK I }\end{array}$} & & \multicolumn{3}{|l|}{ Aspecific mean $C \mathrm{t}$} \\
\hline & & & BK II & BK III & BK IV \\
\hline $10^{7}$ & $17.36(0.07)$ & & $32.16(0.34)$ [32.06] & & \\
\hline $10^{5}$ & $24.12(0.07)$ & & $38.8(0.16)[38.75]$ & & 38.13 \\
\hline $10^{3}$ & $30.9(0.51)$ & & & & \\
\hline \multirow[t]{2}{*}{10} & 36.12 & & & & \\
\hline & BK II & BK I & BK III & & \\
\hline $10^{7}$ & $16.85(0.04)$ & & $36.57(0.62)$ [36.39] & & [32.10] \\
\hline $10^{5}$ & $23.21(0.04)$ & & & & {$[35.75$} \\
\hline $10^{3}$ & $29.97(0.19)$ & 36.14 & 37.74 & & {$[36.24]$} \\
\hline \multirow[t]{2}{*}{10} & 36.03 & & 40.89 & & \\
\hline & BK III & & BK II & & \\
\hline $10^{7}$ & $17.78(0.16)$ & & & & [35.36] \\
\hline $10^{5}$ & $24.2(0.16)$ & & & & \\
\hline $10^{3}$ & $30.84(0.03)$ & & & & \\
\hline \multirow[t]{2}{*}{10} & $37.62(0.63)$ & & 36.91 & & {$[38.40]$} \\
\hline & BK IV & BK I & BK II & & \\
\hline $10^{7}$ & $17.67(0.03)$ & & $36.12(0.81)$ [35.89] & & {$[35.71]$} \\
\hline $10^{5}$ & $24.74(0.01)$ & & & & \\
\hline $10^{3}$ & $32.3(0.19)$ & 36.78 & & & \\
\hline
\end{tabular}

The values in the round brackets are the standard deviations of the repetitions for each dilution; in the square brackets the $\mathrm{C} t_{\mathrm{lim}}$ are reported (see text for explanation)

gap of approximately $14.8-14.68 C \mathrm{t}_{\mathrm{s}}$ separated the specific and aspecific amplifications; moreover, no aspecific amplification was evidenced for lower dilution.

BKV II genotype mix that resulted was able to amplify the specific BKV II target sequence;' however, this was also amplified by the other three BKV discriminating mixes. Only the amplification of the BKV II-specific target with the corresponding mix was linear, and the threshold crossing appeared at least 15 cycles earlier for BKV II mix at $10^{7}$ copies/reaction compared to the other amplification mixes, decreasing to six cycles at $10^{3}$ copies/reaction. The amplification with BKV II mix at lower BKV II genotypespecific target concentration was considered not discriminating, because of the overlapping $\mathrm{Ct}$ with BKV III and IV amplification mixes. The BKV III target was recognized by the corresponding mix with a linear amplification; however, $10^{7}$ copies/reaction were recognized also by the BKV I mix, although a mean gap of $17.84 \mathrm{Ct}_{\mathrm{s}}$ was observed between specific and aspecific amplifications. An undistinguishable specific amplification was seen with a concentration of BKV III of 10 copies/reaction, because of the simultaneous amplification with BKV II, III, and IV mixes with a similar $C \mathrm{t}$. The BKV IV target showed a specific recognition using the corresponding mix, although the target was also amplified with BKV II and III mixes at $10^{7}$ copies/reaction, with a mean gap of 18.21 and $18.45 \mathrm{Ct}_{\mathrm{s}}$ between specific and aspecific amplifications for BKV II and III mixes, respectively. However, at a concentration of $10^{3}$ copies/reaction, the target was also recognized by BKV I mix with a mean gap of 4.48 mean $C \mathrm{t}_{\mathrm{s}}$.

Using the same data to evaluate the specific and aspecific amplifications, a $C \mathrm{t}_{\mathrm{lim}}$ was calculated for each genotyping amplification, as an interference limit (Table 3 ). The precision was calculated with the intra- and inter-test coefficients of variation (Table 4).

In order to establish the limit of detection for the four different genotyping amplifications, 10-fold dilutions of the targets (ranging from $10^{7}$ to 10 copies/reaction) were amplified with the above four methods. The limit of detection differed between the four genotyping amplification procedures and was as follows: $10^{2}$ copies/reaction for BKV IV and 10 copies/reaction for BKV I, II, and III, each. However, only BKV III procedure showed a sensitivity of 10 copies/reaction, while for the others assay, it was of 100 copies/reaction.

Results for the clinical specimens are reported in Table 5. In brief, the amplification procedures yielded positive results

$\begin{array}{lll}\text { Journal : Large 12033 } & \text { Dispatch : 16-2-2011 } & \text { Pages : } 8 \\ \text { Article No. : } \mathbf{9 3 8 6} & \square \text { LE } & \square \text { TYPESET } \\ \text { MS Code : MOBI-D-11-00032 } & \checkmark \text { CP } & \checkmark \text { DISK }\end{array}$


Table 3 Interference limit

\begin{tabular}{lllll}
\hline & $10^{7}(\%)$ & $10^{5}(\%)$ & $10^{3}(\%)$ & $10(\%)$ \\
\hline I-II & 0.00375 & 0.00393 & & \\
II-III & 0.00013 & & & \\
II-IV & 0.00257 & 0.01674 & 1.27874 & \\
III-IV & 0.00051 & & & 36.83754 \\
IV->II & 0.00033 & & & \\
IV-III & 0.00037 & & &
\end{tabular}

The lowest limit of quantity of BKV-specific genotype, expressed in percentage, distinguishable from the background (aspecific amplification). In the case of no reported percentage, sporadic or no background amplification was observed

Table 4 Intra- and inter-assay coefficients of variation for dilutions of $10^{7}, 10^{5}$, and $10^{3}$, and 10 copies/reaction

\begin{tabular}{|c|c|c|c|c|}
\hline & $10^{7}(\%)$ & $10^{5}(\%)$ & $10^{3}(\%)$ & $10(\%)$ \\
\hline \multicolumn{5}{|c|}{ Coefficient of intra-assay variation } \\
\hline I & 0.40 & 0.29 & 1.65 & \\
\hline II & 0.23 & 0.17 & 0.63 & \\
\hline III & 0.89 & 0.66 & 0.10 & 1.67 \\
\hline IV & 0.16 & 0.04 & 0.59 & \\
\hline \multicolumn{5}{|c|}{ Coefficient of inter-assay variation } \\
\hline I & 0.92 & 2.70 & 0.84 & 1.85 \\
\hline II & 1.19 & 0.15 & 1.45 & 0.99 \\
\hline III & 1.30 & 1.51 & 0.91 & 2.92 \\
\hline IV & 3.34 & 2.20 & 2.26 & \\
\hline
\end{tabular}

in 16 cases; in particular: 12716 BKV I, 1/16 BKV II, 1716 BKV III, and 1/16 BKV IV. The DNA sequencing confirmed the results obtained with the Real-Time PCR assays for all the samples. One specimen (\#4464) showed a concomitant amplification for BKV I and BKV IV, with overlapping $\mathrm{Ct}_{\mathrm{s}}$; sequencing identified it as BKV I genotype.

In most of the cases, the viral load found with the developed methods differed from that obtained with the reference method, with a percentage of variation ranging from -288.4 to $89.9 \%$ (Table 5). Furthermore, more aspecific amplifications were observed in clinical specimens. In fact, the sample \#2998 showed two aspecific plots (BKV I and BKV II), while no BKV I amplification was observed with a $10^{7}$ copies/ reaction plasmid dilution. Nevertheless, the occurrence of aspecific amplifications did not impact on the genotyping performance of the Real-Time PCRs, as the gap between the curves of amplifications remained wide.

\section{Discussion}

In this study, a Real-Time PCR-based method for genotyping of polyomavirus BK was developed. By hemagglutination inhibition tests, four main BKV serotypes were described [5], based on the differences in a short amino acidic sequence on VP1 protein, probably being responsible for the serotypical differences among BKV variants [18]. Correspondingly, four main BKV VP1 genotypes were found, and their nucleotide sequences analyzed [18]. On the basis of this conserved region, 379 VP1 sequences were collected from three different articles [8-10] investigating the prevalence of BKV subtypes in different countries, including Germany, Japan, and China. These sequences were aligned to determine which nucleotide residues were conserved within each genotype with the aim to design a Real-time PCR assay based on the principle of the Amplification Refractory Mutation Assay (ARMS).

A complete list of single nucleotide polymorphisms in the total BKV genome for each genotype has been reported [19]. The 379 aligned VP1 sequences presented concordant residues with those previously listed by Luo and colleagues [19], confirming the uniqueness and conservation of these polymorphisms among the genotypes.

It has been reported [19] that genotyping on large $\mathrm{T}$ antigen (LTA) is preferable, in particular, because LTA is a larger region with more informative sites compared to the 327 bp of VP1 region considered by Jin and colleagues [6]. However, in this study, we chose to use the VP1 region instead of LTA as we aimed to produce powerful discriminating Real-Time PCRs taking into consideration the data published in the literature. Indeed, a higher number of sequences is banked in public domain servers for VP1 compared to LTA, thus permitting a more detailed primersand-probes design for the detection of a higher number of sequences and corresponding polymorphic residues. In this study, four Real-Time PCR assays, each one that can amplify specifically a specific genotype, were designed, and four different amplification mixes were produced to avoid a too high concentration of primers in a single well, that could determine dimer formation or an increase in the aspecific performance. In fact, in the presence of high viral loads, aspecific amplifications might appear, and these were detectable as a low quantity amplification with other genotype mixes; anyway, the aspecific amplification was easily recognizable by the wide gap between the specific and aspecific plots. Moreover, the introduction of $C \mathrm{t}_{\mathrm{lim}}$ and interference limit gave further clues about discrimination. Clearer results were available for $10^{7}-10^{5}$ copies/reaction dilutions, while $10^{3}$ caused the lowest dilution with an acceptable genotyping performance. For this reason, a result comparable to $10^{3}$ was set as genotyping limit for all the four Real-Time PCRs, and all those results with a lower quantity were not accepted.

As regards the clinical validation of the four genotyping assays, the distribution of BKV genotypes was evaluated in

$\begin{array}{lll}\text { Journal : Large 12033 } & \text { Dispatch : 16-2-2011 } & \text { Pages : } 8 \\ \text { Article No. : } \mathbf{9 3 8 6} & \square \text { LE } & \square \text { TYPESET } \\ \text { MS Code : MOBI-D-11-00032 } & \boldsymbol{V}_{\text {CP }} & \checkmark \text { DISK }\end{array}$


Table 5 BK genotyping in clinical specimens

\begin{tabular}{|c|c|c|c|c|c|c|c|c|}
\hline $\mathrm{N}^{\circ}$ & ID & Reference copies/ml & $\mathrm{BKV} \mathrm{I}(C \mathrm{t})$ & $\mathrm{BKV}$ II $(C \mathrm{t})$ & BKV III $(C t)$ & BKV IV $(C \mathrm{t})$ & Genotype & Copies/ml \\
\hline 1 & 2998 & $>5 \times 10^{6}$ & 31.63 & 33.82 & & 11.59 & IV & $>5 \times 10^{7}$ \\
\hline 2 & 3068 & 4237203 & 19.57 & 36.36 & & 32.78 & I & $>5 \times 10^{7}$ \\
\hline 3 & 3204 & 569 & & & & & & \\
\hline 4 & 3206 & $>5 \times 10^{6}$ & 12.01 & 26.65 & & 25.34 & I & $>5 \times 10^{7}$ \\
\hline 5 & 3207 & 2413 & 30.60 & & & & I & $5379(-122.9 \%)$ \\
\hline 6 & 3607 & 126470 & 29.38 & 36.56 & & & I & $12800(89.9 \%)$ \\
\hline 7 & 3619 & 1542 & & & & & & \\
\hline 8 & 3965 & 502131 & 24.72 & 43.06 & & 38.04 & I & $351153(30.1 \%)$ \\
\hline 9 & 4011 & 868 & & & & & & \\
\hline 10 & 4063 & 4158 & 30.14 & & & & I & $7458(-79.4 \%)$ \\
\hline 11 & 4326 & 495 & 34.78 & & & & I & $<500$ \\
\hline 12 & 4398 & 49606 & 29.73 & 43.09 & & 38.53 & I & $9981(79.9 \%)$ \\
\hline 13 & 4405 & 2472943 & 34.93 & 19.80 & & 32.37 & II & $1220410(50.6 \%)$ \\
\hline 14 & 4464 & 8689 & 36.59 & & & 36.69 & I & $<500$ \\
\hline 15 & 4674 & 6441 & 29.22 & 42.79 & & 42.64 & I & $14342(-122.7 \%)$ \\
\hline 16 & 4712 & 2393 & 30.58 & & & 37.65 & I & $5456(-128 \%)$ \\
\hline 17 & 4714 & $<59$ & 36.17 & & & & I & $<500$ \\
\hline 18 & 4723 & $>5 \times 10^{6}$ & 12.19 & 28.37 & & 26.11 & I & $>5 \times 10^{7}$ \\
\hline 19 & 4758 & $<59$ & & & & & & \\
\hline 20 & 4768 & 44562 & & 31.50 & 29.14 & & III & $173076(-288.4 \%)$ \\
\hline
\end{tabular}

Viral loads (expressed in copies $/ \mathrm{ml}$ ) of positives samples for the reference method, positivity to each amplification procedure (expressed in $C \mathrm{t}$ ), genotype and quantities (expressed in copies $/ \mathrm{ml}$ ) are reported. Bold numbers shows $\mathrm{Ct}_{\mathrm{s}}$ of overlapping curves

392

393

394

395

396

397

398

399

400

401

402

403

404

405

406

407

408

409

410 urine specimens; this type of sample was chosen for the higher mean viral load in comparison to serum samples [2]. However, clinical samples with a low reference viral load were not always detected. Most of the specimens were infected by BKV I (80\%), while BKV II, III, and IV were infrequent. The prevalence of the four genotypes was concordant with the literature [20]. BKV IV, that is more prevalent in East Asia [8], is found also in Europe [9] in a percentage comparable to the one observed by us; however, notwithstanding the uncommon prevalence, both BKV II and BKV III were detected in two different samples; the results were confirmed by the subsequent VP1 DNA sequencing.

Considering viral load of different genotypes, a high divergence was observed between the genotyping assays and the reference method, with a variability ranging from -288.4 to $89.9 \%$. These data highlighted the problem exposed by Hoffman and coll. [21]: in the presence of various genotypes, difference in probes and primers for the BKV quantification led to a substantial disagreement between assays. This was confirmed in our study, between the reference and the genotyping amplifications.

In conclusion, the four Real-Time PCRs that were produced were able to detect and discriminate the main four BKV genotypes. Compared to classical DNA sequencing, these procedures are more rapid and simpler, since they are single PCR assays with no purification steps; results are available in approximately $2 \mathrm{~h}$. One drawback could arise because of the need of at least $10^{3}$ copies/reaction for the genotyping; in these cases, a PCR assay employing external primers, or other protocols, would be necessary to increase the target sequence amplifiable, although this should also increase the time required for genotyping.

The comparison between genotyping procedures on clinical samples and plasmid dilutions evidenced some differences, including the detection of aspecific plots during the testing of clinical samples, and the lack of similarity with the quantities reported by the reference amplification procedure. This could be caused by the primers-and-probes nature, amplifying Large T (reference method) and VP1, and by the presence of polymorphism that alter the efficiency of amplification, as previously suggested [21]. Nevertheless, the four Real-Time PCRs developed in this study should not be considered quantitative methods, as the procedures were not tested for the quantification of a broad number of isolates. The availability of a rapid and simple genotyping test could be useful for the evaluation of BKV genotypes' prevalence. and studies on the impact of the infecting genotype on viral biological behavior, pathogenic role, and immune evasion strategies.

\begin{tabular}{lll} 
Journal : Large 12033 & Dispatch : 16-2-2011 & Pages : 8 \\
Article No. : 9386 & $\square$ LE & $\square$ TYPESET \\
MS Code : MOBI-D-11-00032 & $\sim_{\text {CP }}$ & $\checkmark$ DISK \\
\hline
\end{tabular}




\section{References}

444

445

446

447

448

449

450

451

452

453

454

455

456

457

458

459

460

461

462

463

464

465

466

467

468

469

470

471

472

473

474

475

476

477

478

479

480
1. Seif, I., Khoury, G., \& Dhar, R. (1979). The genome of human papovavirus BKV. Cell, 18, 963-977.

2. Costa, C., Bergallo, M., Astegiano, S., Terlizzi, M. E., Sidoti, F., Segoloni, G. P., et al. (2008). Monitoring of BK virus replication in the first year following renal transplantation. Nephrology, Dialysis, Transplantation, 23, 3333-3336.

3. Randhawa, P. S., \& Demetris, A. J. (2000). Nephropathy due to polyomavirus type BK. New England Journal of Medicine, 342, 1361-1363.

4. Rice, S. J., Bishop, J. A., Apperley, J., \& Gardner, S. D. (1985). BK virus as cause of haemorrhagic cystitis after bone marrow transplantation. Lancet, 2, 844-845.

5. Knowles, W. A., Gibson, P. E., \& Gardner, S. D. (1989). Serological typing scheme for BKV-like isolates of human polyomavirus. Journal of Medical Virology, 28, 118-123.

6. Jin, L., Gibson, P. E., Booth, J. C., \& Clewley, J. P. (1993). Genomic typing of BK virus in clinical specimens by direct sequencing of polymerase chain reaction products. Journal of Medical Virology, 41, 11-17.

7. Takasaka, T., Goya, N., Tokumoto, T., Tanabe, K., Toma, H., Ogawa, Y., et al. (2004). Subtypes of BK virus prevalent in Japan and variation in their transcriptional control region. Journal of General Virology, 85, 2821-2827.

8. Chen, Q., Zheng, H. Y., Zhong, S., Ikegaya, H., He, H. X., Wei, W., et al. (2006). Subtype IV of the BK polyomavirus is prevalent in East Asia. Archives of Virology, 151, 2419-2429.

9. Krumbholz, A., Zell, R., Egerer, R., Sauerbrei, A., Helming, A., Gruhn, B., et al. (2006). Prevalence of BK virus subtype I in Germany. Journal of Medical Virology, 78, 1588-1598.

10. Zhong, S., Yogo, Y., Ogawa, Y., Oshiro, Y., Fujimoto, K., Kunitake, T., et al. (2007). Even distribution of BK polyomavirus subtypes and subgroups in the Japanese archipelago. Archives of Virology, 152, 1613-1621.

11. Tobler, A. R., Short, S., Andersen, M. R., Paner, T. M., Briggs, J. C., Lambert, S. M., et al. (2005). The SNPlex genotyping system: a flexible and scalable platform for SNP genotyping. Journal of Biomolecular Techniques, 16, 398-406.
12. Mukai, H., Takeda, O., Usui, K., Asada, K., \& Kato, I. (2008). SNP typing of aldehyde dehydrogenase 2 gene with Cycleave ICAN. Molecular and Cellular Probes, 22, 333-337.

13. Li, J., Wang, L., Jänne, P. A., \& Makrigiorgos, G. M. (2009). Coamplification at lower denaturation temperature-PCR increases mutation-detection selectivity of TaqMan-based real-time PCR. Clinical Chemistry, 55, 748-756.

14. Aomori, T., Yamamoto, K., Oguchi-Katayama, A., Kawai, Y., Ishidao, T., Mitani, Y., et al. (2009). Rapid single-nucleotide polymorphism detection of cytochrome P450 (CYP2C9) and vitamin $\mathrm{K}$ epoxide reductase (VKORC1) genes for the warfarin dose adjustment by the SMart-amplification process version 2 . Clinical Chemistry, 55, 804-812.

15. Newton, C. R., Graham, A., Heptinstall, L. E., Powell, S. J., Summers, C., Kalsheker, N., et al. (1989). Analysis of any point mutation in DNA. The amplification refractory mutation system (ARMS). Nucleic Acids Research, 17, 2503-2516.

16. Mattarucchi, E., Marsoni, M., Binelli, G., Passi, A., Lo Curto, F., Pasquali, F., et al. (2005). Different real time PCR approaches for the fine quantification of SNP's alleles in DNA pools: assays development, characterization and pre-validation. Journal of Biochemistry and Molecular Biology, 38, 555-562.

17. Germer, S., Holland, M. J., \& Higuchi, R. (2000). Highthroughput SNP allele-frequency determination in pooled DNA samples by kinetic PCR. Genome Research, 10, 258-266.

18. Jin, J., Gibson, P. E., Knowles, W. A., \& Clewley, J. P. (1993). BK virus antigenic variants: sequence analysis within the capsid VP1 epitope. Journal of Medical Virology, 39, 50-56.

19. Luo, C., Bueno, M., Kant, J., Martinson, J., \& Randhawa, P. (2009). Genotyping schemes for polyomavirus BK, using genespecific phylogenetic trees and single nucleotide polymorphism analysis. Journal of Virology, 83, 2285-2297.

20. Zheng, H. Y., Nishimoto, Y., Chen, Q., Hasegawa, M., Zhong, S., Ikegaya, H., et al. (2007). Relationships between BK virus lineages and human populations. Microbes and Infection, 9, 204-213.

21. Hoffman, N. G., Cook, L., Atienza, E. E., Limaye, A. P., \& Jerome, K. R. (2008). Marked variability of BK virus load measurement using quantitative real-time PCR among commonly used assays. Journal of Clinical Microbiology, 46, 2671-2680.

\begin{tabular}{|l|lll|}
\hline Journal : Large 12033 & Dispatch : 16-2-2011 & Pages : 8 \\
Article No. : $\mathbf{9 3 8 6}$ & $\square$ LE & $\square$ TYPESET \\
& MS Code : MOBI-D-11-00032 & $\sim_{\text {CP }}$ & $\checkmark$ DISK \\
\hline
\end{tabular}

